\title{
O renminbi no pós-crise: a condução e a estratégia do processo de internacionalização da moeda após a crise financeira de 2008 frente ao poder do dólar americano
}

O renminbi no pós-crise: a condução e a estratégia do processo de internacionalização da moeda após a crise financeira de 2008 frente ao poder do dólar americano

Bruno Haeming ${ }^{3}$

DOI: $10.5752 /$ P. 1809-6182.2018v15.n2.p41

Recebido em: 06 de setembro de 2018 Aceito em: 11 de dezembro de 2018

\section{Resumo:}

O presente artigo trata da internacionalização da moeda chinesa, o Renminbi, no periodo pós crise de 2008 dentro do contexto da hegemonia do dólar. Percebeu-se o poder monetário americano aumentado após a crise, e a China com relativos avanços, mas com sua moeda muito menos utilizada do que o dólar.

Palavras-Chave: Pós Crise de 2008. Dólar. Renminbi.

\section{Abstract:}

This paper assess the internationalization of Chinese currency, Renminbi, after the 2008 crises in the context of dollar's hegemony. The results display an increased American monetary power, and also China displayed a relative improvement in its currency international usage, although it is far below than dollar international utilization.

Keywords: Post 2008 crises. Dollar. Renminbi.

3. Doutorando em Relaçōes Internacionais na PUC MG (Pontifícia Universidade Católica de Minas Gerais) e bolsista CAPES. Belo Horizonte, Brasil. ORCID - https://orcid.org/0000-0002-7268-2528. 


\section{INTRODUÇÃO}

O presente trabalho pretende analisar o processo de internacionalização da moeda chinesa, o Renminbi, em especial nos eventos do pós crise financeira de 2008. Entende-se que existe uma importância central para a moeda enquanto ferramenta de promoçáo do desenvolvimento e proteçáo contra tentativas externas de competição macroeconômica e monetária. Dentro das ambições chinesas de se expandir internacionalmente, conta com uma economia e com moeda forte.

Essa discussão engloba o poder americano, dado que os Estados Unidos da América (EUA) são a maior potência monetária, com o ambiente de possível rivalidade monetária.

O papel da China é de "intruso" nesse contexto. As condiçôes para que sua moeda seja internacionalizada são bastante desafiantes no que diz respeito aos riscos ao seu projeto de desenvolvimento, dado que mudanças na sua política macroeconômica podem influenciar sua competitividade internacional. Levando em conta o exposto, pergunta-se: Houve avanços no uso internacional do RMB desde a crise de 2008?

Para tratar do problema, o texto será divido em três partes; i) Uma breve descrição do sistema monetário internacional no pós-crise, eventos relevantes e o status do dólar americano; ii) a partir disso, buscar-se-á compreender o uso internacional da moeda chinesa, o $\mathrm{RMB}$, a trajetória da estratégia de internacionalização no pós crise, assim como ; iii) as perspectiva para o uso do RMB, os avanços e possíveis retrocessos assim como o debate acerca dessa estratégia da China.

\section{O sistema monetório e financeiro internacional no pós-crise de 2008}

Após 2008 houve elevada desconfiança mundial em relação ao dólar americano e a capacidade dos Estados Unidos da América (EUA) em reverter o quadro de "derretimento" do seu mercado financeiro derivado da crise do sub-prime. Porém, tal visão pessimista em relação ao dólar não se confirmou, e isso se deve a economia política da moeda américa.

Desde fim do padrão ouro-dólar (e início do chamado padrão dólar-flexível), a moeda americana se sustenta em torno da capacidade dos EUA em manter seu sistema financeiro como um dos elementos centrais da sua economia, o que lhe dá um "privilégio exorbitante" ${ }^{4}$ na medida em que a macroeconomia mundial fica sob a tutela da sua política econômica e monetária, também se coloca como elemento principal dessa dinâmica o seu mercado financeiro. É em função desse mercado que os EUA conseguem, a nível global, direcionar para si uma enorme quantidade de recursos financeiros, provendo rentabilidade e segurança para os investidores: em suma os EUA captam recursos a curto e provem à longo prazo através da enorme liquidez, complexidade e desenvolvimento do seu mercado financeiro (BRAGA, 1997; SERRANO, 2002; BRAGA e CINTRA, 2004).

Kaltenbrunner e Lysandrou (2017) aprofundam a questáo do desenvolvimento dos mercados financeiros americano, tanto os mercados primários e secundários - esses negociando diversos tipos de modalidades financeiras como títulos e derivativos - a ponto de fazer com que (e principalmente) os títulos financeiros sejam táo líquidos quanto qualquer outro ativo, inclusive a própria moeda. Ao fim e ao cabo, a grande variedade de ativos, a complexidade e a profundidade que a estrutura financeira atrelada ao dólar possui, torna uma "obrigação" para empresas e investidores do mundo inteiro deterem ativos em dólar.

Todavia, em função do tamanho da crise financeira de 2008, uma série de contestaçóes do status americano foram postas. Helleiner (2010) lê

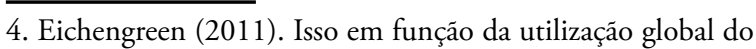
dólar americano. 
esse momento como mais uma etapa de um processo de contestação da "globalização financeira" ${ }^{5}$, muito em virtudes das crises serem recorrentes. $\mathrm{O}$ protagonismo de instituições como o G20 (com uma liderança de países dos BRICS) e sua atuação no FMI a partir de uma agenda propositiva de reformas do Sistema Financeiro e Monetário Internacional (SFMI), seriam um indício de aumento relativo de poder desses países e a possibilidade de mudanças. Com o cômodo afastamento temporal, é possível perceber que dos países considerados $R i$ sing Powers ${ }^{6}$ apenas a China tem a sua frente um caminho menos nebuloso rumo ao desenvolvimento (STEPHEN, 2014).

A gradual contração esperada para o dólar, até o momento não ocorreu. Em Kirshner (2009) e (2016) defende-se a ideia de que a crise financeira gera um espaço de dúvida, aprendizado e aumento das demandas por espaço e autonomia no sistema internacional por outros Estados, em especial no campo monetário. Mesmo o autor reiterando a dificuldade de se arcar com uma "heterogeneidade monetária”, os elementos econômicos e geopolíticos (militares) para a sustentação do poder americano podem sofrer uma relativa queda.

$\mathrm{O}$ argumento de Kirshner (2016) não se limita a questão monetária, e dessa forma deve ser visto com maior cautela. Todavia é a moeda um dos pilares fundamentais do poder americano, e 10 anos se passaram e o poder da moeda americana, e a "preferência" por ela não diminuiu, ao contrário, aumentou.

A operacionalização da resiliência do dólar foi feita através do movimento coordenado pelos EUA de “injeção" de liquidez na economia mun-

5. Se remete às mudanças ocorridas com o final do padrão ouro-dólar, em que as finanças se tornaram globais e isso trouxe instabilidade e crise para o capitalismo.

6. Em especial os BRICS ( Brasil, Rússia, Índia, China e África do Sul). dial através do seu Banco Central, o FED ${ }^{7}$. Em suma, os EUA assumiram um papel inédito de “emprestador de última instância”, atuando conjuntamente com 14 Bancos Centrais do mundo inteiro, utilizando operaçóes de swap cambial, o que possibilitou linhas de swap que partiu linhas de 15 bilhóes de dólares, chegando ao pico de 600 bilhóes negociados. Dito de outra forma, o FED virou o Banco Central do mundo, inundando todos os cantos de dólares, buscando se defender de uma exposição financeira, e de alteraçóes indesejadas na sua taxa de juros e câmbio (MCDOWELL, 2012).

O movimento "racional" seria de fugir do lugar e do agente causador da crise, grosso modo. Porém, os Estados aumentaram gradativamente suas posições em dólar até o período mais recente do primeiro trimestre de 2018, como é possível notar Gráfico1.

A China também respondeu à crise. Mesmo sofrendo impactos no seu comércio, sua resposta se deu aliando uma estratégia de expansão econômica e monetária, como se perceberá nas próximas seções.

\section{Estratégia chinesa para o pós- crise e a internacionalização do RMB}

Como foi possível observar na seção anterior, a China necessita lidar com um SFMI dominado pelas finanças e liderado pelos EUA desde o final do padrão ouro-dólar ${ }^{8}$, e que não sofreu um rompimento na sua lógica mesmo após a crise de 2008.

7. Federal Reserv, o Banco Central dos EUA.

8. O dólar como moeda referência (e dominante no SFMI) vem desde os acordos de Bretton Woods, porém a dominação através das finanças é o marco temporal adotado aqui, em que tem no final da paridade padráo ouro-dólar em 1971 o seu fim. Entretanto, em 1979, há a retomada da hegemonia do dólar, que se entende aqui como o momento mais contundente do processo de expansão das finanças e do (re)posicionamento americano como a maior liderança do sistema internacional, e colocando de lado eventuais contestaçóes. 
Grófico 1. Composição mundial de reservars internacionais (em milhões de US\$)

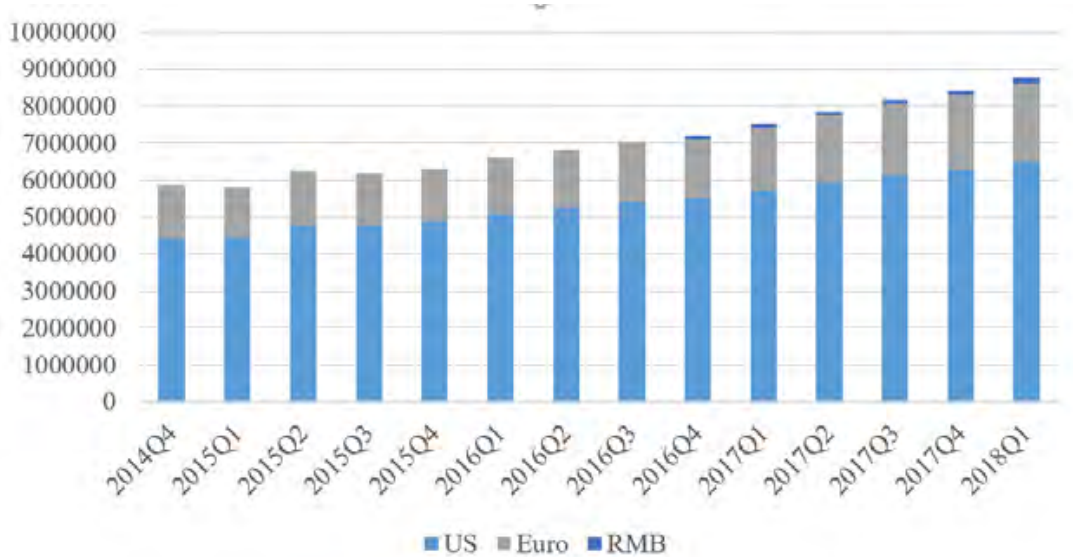

Fonte: Elaborado pelo autor com dados de COFER- FMI. (Disponível em http://data.imf.org, acesso em 21/08/18.)

A China possui um projeto de se tornar uma potência a nível regional e internacional, não necessariamente em desafio aos EUA, mas ocupando espaços de maior prestigio na economia, na segurança e nas instituiçóes, promovendo alianças e construindo meios de se consolidar internacionalmente (SCHWELLER, 2018).

Para que um país seja uma potência, necessita que sua moeda seja utilizada a nível internacional. Se isso ocorrer dentro da lógica do SFMI vigente, será necessária uma maior participação das finanças no capitalismo chinês. Isso acontece pois moedas internacionalizadas e amplamente utilizada possuem certas características que lhe conferem maior utilização pelos agentes.

Em primeiro lugar, a moeda para ser mais utilizada precisa desempenhar as funçôes i) unidade de conta, ii) meio de troca e iii) reserva de valor. Isso deve acontecer tanto na esfera privada, quanto na esfera estatal: empresas e investidores, juntamente com outros países devem estar dispostos a reter e usar a moeda (COHEN, 1971). Para que uma moeda seja utilizada internacionalmente ela deve possuir; i) confiabilidade, ii) liquidez e iii) redes transacionais para sua utilização em negócio e no comércio (HELLEINER, 2008). Como será abordado mais a frente, a China aposta que tanto as funçóes quanto as caracte- rística que conferem maior utilização a moeda serão atingidas por uma larga utilização comercial (Belt and Road Initiatie), e através de mercados financeiros offshore.

Os países desejam que sua moeda seja usada internacionalmente em função de uma série de vantagens econômicas e políticas, como é possível verificar no caso de países de moeda "forte". Criam-se espaços de uso da moeda, que dão um caráter permissivo e de poder ${ }^{9}$ para o país emissor (COHEN, 1998). Todavia, no caso de Alemanha e Japão, viu-se que tal processo não é trivial. Esses países trilharam a rota de internacionalização de suas moedas, buscando ascensão no cenário internacional monetário e econômico, porém não se propuseram a arcar com os custos de desenvolver um mercado financeiro complexo somado a desregulamentaçáo dos fluxos de capitais (HELLEINER e KIRSHNER, 2009; COHEN, 2011).

Uma justificativa para o caso de Alemanha e Japão seria o receio de se perder o controle da política monetária e dos fluxos financeiros, que usualmente é conhecido como trilema ${ }^{10}$.

\footnotetext{
9. O conceito de poder monetário de Cohen (1998), está nos "espaço autorizativos", ou na geografia política de influência da moeda de um Estado no espaço em que circula.

10. O trilema diz respeito a uma combinação "impossível" de conservar taxas de câmbio fixas, livre fluxo de capitais e autonomia da política monetária.
} 
No caso da China, há um grande apreço pela autonomia na sua política de preços macroeconômicos, e ao longo da história se percebe que uma maior liberalização dos fluxos financeiros e do câmbio traz maior instabilidade para o país (CINTRA e PINTO, 2017).

Subacchi (2010) aponta para a internacionalização como uma forma de tirar a China de uma trajetória de grande dependência (ou interdependência) em relação aos EUA. Há um vínculo comercial forte entre os países, e pela posiçâo chinesa de comercializar com os americanos e com o resto do mundo em dólar, possuem uma reserva internacional dessa moeda de aproximadamente 3,12 trilhôes de dólares ${ }^{11}$ : em suma, a China se vê impelida a financiar um modelo de SFMI instável. A internacionalização seria uma maneira de diminuir relativamente o vínculo da China com a economia política do dólar.

É verdade que a China não possui uma experiência na internacionalização monetária, e de fato poucos países possuem, muito pela limitada quantidade de países com moeda conversível ${ }^{12}$. Os desafios que se colocam perante a China são de grande monta: i) lidar com a acachapante importância do dólar frente a outras moedas, ii) incentivar que os agentes estatais e privados utilizem o RMB em um cenário tão adverso. Todos esses fatos não significam que o caminho seja intransponível, ao contrário, a China deve perseguir tal objetivo e encontrar seus próprios meio para internacionalizar sua moeda, sem necessariamente perder sua autonomia (SUBACCHI, 2010).

McNally e Gruin (2017) reiteram que é necessária a criação de novos caminhos para que a aceita-

11. PBoC ( Peoples Bank of China).

12. Aqui se adota o termo moeda conversível com intuito de falar de moedas em que os agentes estatais ou privados podem tomar posição naquela moeda e sair no momento em que desejarem. A China atualmente detêm o controle da quantidade e do tipo de fluxos de capitais que entram e saem do país, dessa forma deter ativos em RMB e se desfazer deles é mais complicado do que em outras economias. çấo do RMB aconteça. Ao longo do tempo a China mostrou capacidade de adaptar a sua dinâmica de crescimento e desenvolvimento ao mercado e a outros Estados, assim como os agentes se adaptaram as particularidades e à visão estratégica da chinesa de buscar seus interesses. Logo, se é verdade que a China não possui expertise em transitar no mundo das finanças e das moedas internacionalizadas, também é verdade que ela é capaz de transformar dificuldades ao seu redor a seu favor.

No horizonte há duas formas principais para atrair os agentes e aumentar o uso do RMB: i) incentivar o uso do RMB através do comércio internacional, e ii) expandir e tornar mais complexo os mercados financeiros em RMB, em especial os offshore.

\section{O comercio da China com o mundo e o uso do $R M B$}

Como mencionado, as redes transacionais são condição necessária para que uma moeda seja amplamente utilizada. Dessa forma a criação de vínculos bilaterais ou multilaterais condicionados ao uso de uma moeda se tornam relevantes como estratégia de internacionalização.

Gagnon e Troutman (2014) mostram que há da parte chinesa uma alta capacidade em estabelecer acordos comerciais que culminam com uso preferencial do RMB. Essa capacidade anda em conjunto com um controle dos limites da expansão das bases monetárias chinesas em sua praça financeira em Hong Kong em relação a moeda criada em seu território: o governo usa tal controle para evitar aumentos desnecessários em sua base monetária e proteger o seu câmbio de valorizaçóes deletérias à sua competitividade.$^{13}$

Todavia há um movimento relevante do pós crise de queda nas exportações e importaçôes chinesas;

13. Cabe lembrar que a China possui um regime cambial diferenciado na sua praça financeiras de Hong Kong, em que a sigla do preço da moeda é CNH. Já o câmbio dentro da China é denominado de CNY. 
Grófico 2. Importação e Exportação Chinesa 2000-2016 (\% do PIB).

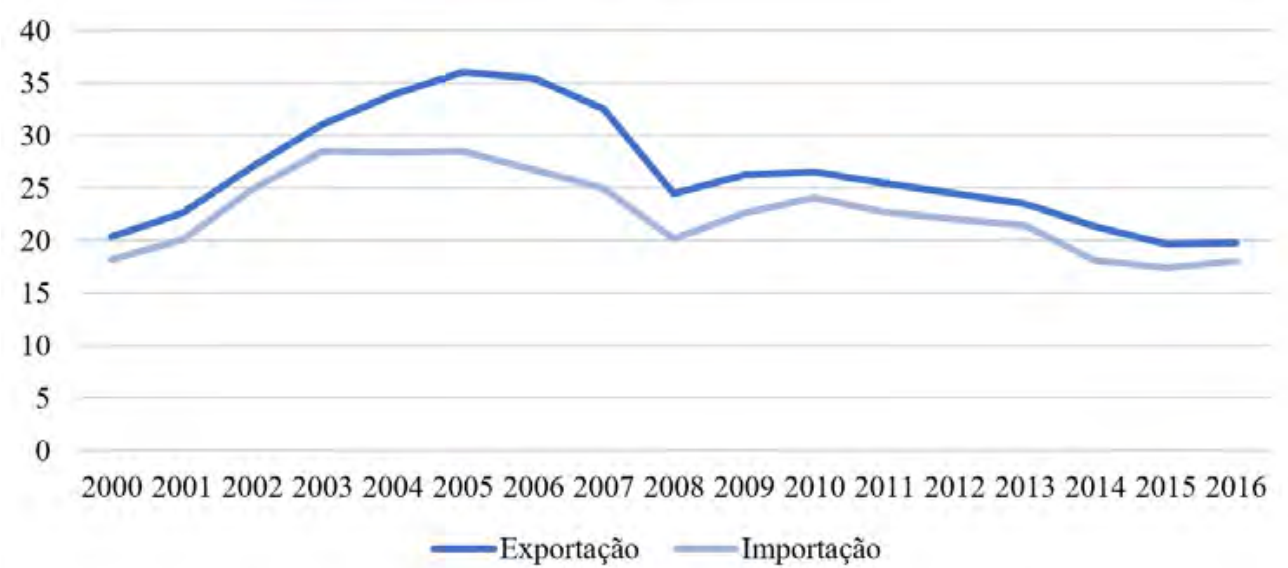

Fonte: Elaborado pelo autor com dados de World Bank (Disponível em http://databank.worldbank.org/, acesso em 25/08/18.)

Tal processo, ilustrado pelo Gráfico 2, aponta um decrescimento de exportaçôes e importações em termos relativos, vai da retração do comércio mundial à uma orientação da China "para dentro" em decorrência do aumento da sua classe média e, consequentemente, do mercado consumidor.

Logo, na dinâmica capitalista chinesa, percebe-se uma mudança gradativa de modelo de crescimento, diminuindo a orientação export-led e apostando na melhoria da inserção chinesa nas cadeias globais de valor (global value chains) e melhorando seu perfil de comércio com o mundo e na região asiática ${ }^{14}$ (YUAN, 2017).

Dentro da lógica da melhora do perfil do comércio chinês, está o seu engajamento na competição com países como os EUA em tecnologias de ponta, em especial a Inteligência Artifical, o que no futuro pode render uma ascensão na divisão internacional do trabalho (WANG e CHEN, 2018)

Não apenas a China mira na estruturação de um mercado doméstico ativo, e investindo em alta

14. Yuan (2017) aponta a tendência de agregação de valor a sua produçáo de manufatura chinesa. Os dados do Banco Mundial mostram uma queda de 6,5\% na agregaçáo de valor em \% do PIB de 2008 a 2017, porém uma positiva Formação Bruta de Capital de 2,2\% do PIB. Logo, mesmo com a mudança de perfil do comércio e a perda relativa em agregação de valor, a China busca manter sua capacidade de gerar produção industrial de tecnologia mais avançada. tecnologia para ser mais competitiva, mas não faz isso apenas olhando para dentro, mas para fora. A Belt and Road Iniciativel5 (BRI) é um caminho para que os "gargalos" das mudanças produtivas e sociais do modelo de desenvolvimento chinês sejam sanados, e a moeda do país seja cada vez mais transacionada. Sua importância vem da interpretação de que será possível estabelecer uma ampla gama de relações comerciais, em que o nível de comércio denominado em RMB e de acordos comerciais fechados na moeda chinesa aumentarão. $\mathrm{O}$ comércio da China com os países da BRI já chega perto de 1 trilhão de dólares, e com os investimentos que são esperados, as expectativas são de que o número cresça substancialmente (LIN et al., 2017).

Para viabilizar os investimento na BRI, o governo chinês contará com instituiçôes financeiras estatais, como o (Asian Infraestructure Investment Bank) AIIB, o Banco do BRICS , o NDB ( New Development Bank) e instituições financeiras privadas. Da mesma forma, haverá um fomento dos mercados financeiros offshore, que através de um mecanismo de compensaçôes em RMB e da emis-

15. Conhecida também como a "Nova Rota da Seda". É uma rota comercial que inclui investimentos em infraestrutura $\mathrm{e}$ transporte, com um "braço" terrestre que vai da China até a Holanda, passando pelo Oriente médio. O "braço" Marítimo pega o Quênia, subindo o Oceano Índico no norte da África até a Itália. 
são de títulos e outras modalidades financeiras denominadas na moeda chinesa, transformar-se-á em um incentivo para o uso do RMB pelos outros agentes e Estados, que confere a moeda maior liquidez e confiabilidade (LIN et al. , 2017 ; SUBACCHI; OXENFORD, 2017).

\section{Os Mercados Financeiros Offshore chineses}

Em simbiose com a BRI, o governo chinês aposta nos seus mercados financeiros offshore ${ }^{16}$ como meio de incentivar o uso internacional da sua moeda. O mercado financeiro offshore foi criado em 2004 pelo governo chinês em Hong Kong, e como mostra Cohen (2012) a percepção do Banco Central chinês passou a ser mais incisiva a partir de 2006, e após a crise o direcionamento para aprofundar a utilização das praças financeiras ficou mais evidente. Os primeiros títulos denominados em RMB no mercado offshore foram emitidos em 2007, e foram chamados de Dim Sum Bonds.

Subacchi e Oxenford (2017) asseveram que a estratégia mais incisiva se iniciou em 2009, tanto como uma forma de conciliar o projeto estratégico da China em possuir uma moeda internacional e seus benefícios, quanto uma maneira de diminuir o faturamento e compensação em dólar da economia chinesa no comércio.

Todavia, o processo se deu com uma série de restriçôes por parte do governo chinês, que iam da criação de um regime diferenciado de câmbio, internamente chamado de CNY e para os ativos emitidos em Hong Kong $\mathrm{CNH}$, até restriçóes no repatriamento da moeda chinesa por residentes. Ao longo do tempo houve uma flexibilizaçáo do uso do RMB offshore relacionada as instituiçóes emissoras de títulos denominados em RMB, compensaçôes bancárias e investimentos. Uma futura liberalização

16. Há mercados Offshore em Hong Kong, Londres, Cingapura. Por ser mais relevante, o trabalho focará nos movimentos de RMB em Hong Kong. dos mercados offshore para o onshore é algo difícil de imaginar, mas gradativos aumentos do uso da moeda, e da complexidade do mercado offshore, contando com mercados secundários mais líquidos, é factível (SUBACCHI; OXENFORD, 2017).

\section{Dilemas da internacionalização do RM e perspectivas}

O processo de internacionalização sofreu alguns contratempos, como mostra a figura a seguir;

Figura 1. Comércio Internacional denominado em RMB x Porticipação dos

Negócios Fechado em RMB frente ao restonte do mundo.

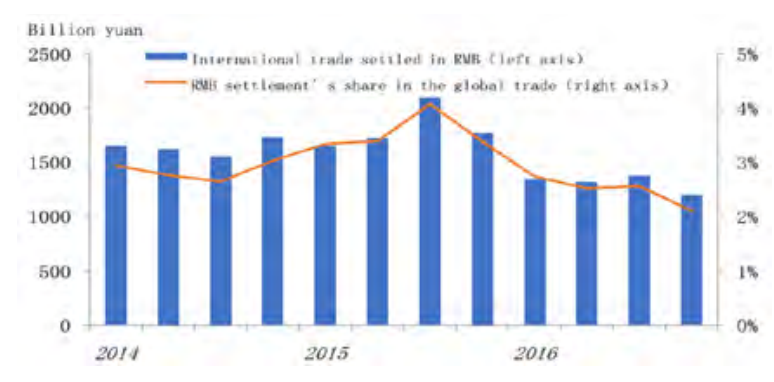

Fonte: SWIFT apud IMI, 2017.

Como é possível observar na Figura 1, tanto houve decrescimento na no uso do RMB para o comércio internacional, quanto uma queda nos negócios internacionais fechados em RMB em relação ao restante do mundo. Isso se relaciona com o dado do Gráfico 2, que mostra a queda do fluxo comercial da China, fato que tem relação com a retração do comercio mundial como um todo.

Entretanto, há a perspectiva de aumento do uso do RMB internacionalmente pelo fechamento de contratos denominado em RMB, isso em função do tamanho da economia chinesa, retomada do comércio internacional e pelas possibilidades que BRI trazem em termos de volume negociado em RMB, 
Grófico 3. Depósitos Totơis em RMB por mês (Milhões de Yuon)

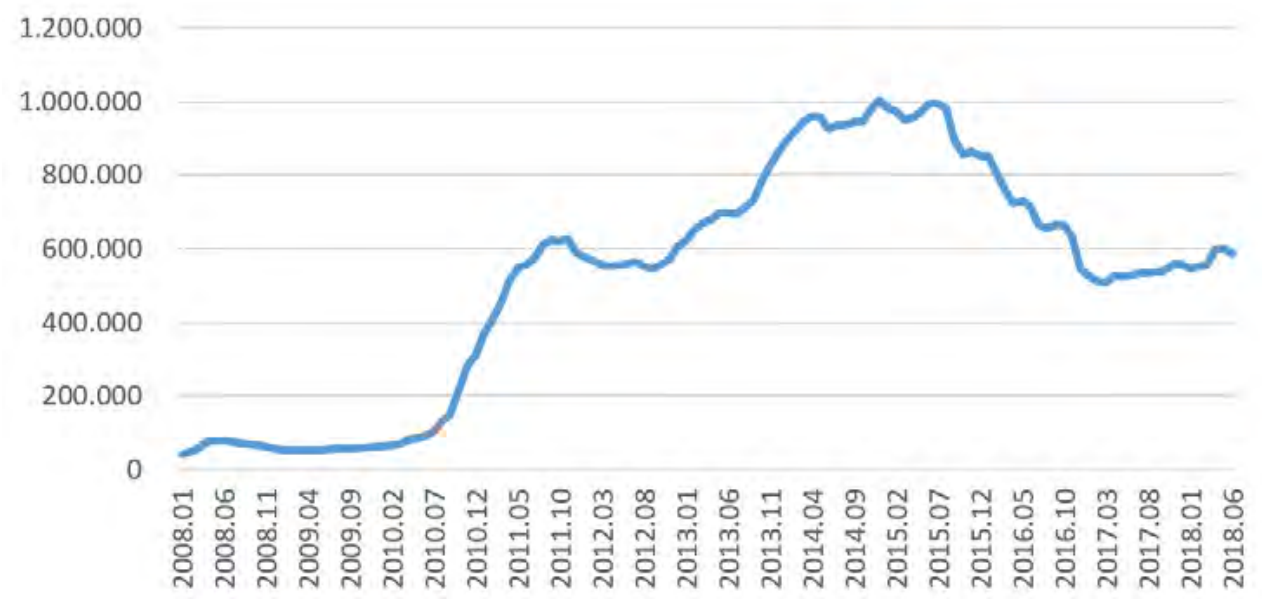

Fonte: Fonte: Elaborado pelo autor com dados de HKMA, 2018.

haja vista a escala e o escopo do projeto (LIN et al. 2017; SUBACCHI; OXENFORD, 2017).

Do lado financeiro, também se percebeu um arrefecimento do uso do RMB nas praças financeiras offshore que começou ao final de 2015, porém com uma retomada nos anos posteriores;

Apesar da queda em 2015, há uma clara tendência do aumento do uso da moeda chinesa na sua maior praça financeira offshore - Hong Kong. Isso pode ser explicado pela crescente corrida mundial para o dólar mencionada na primeira seção( o dólar é bastante demandado em períodos de incerteza), seja pela incerteza eleitoral do período 2015-2016, ou pela mudança na política do FED de aumento da sua taxa básica de juros, que elevou o uso da greenback como é possível observar no Gráfico 1.

IMI (2017) levanta a possibilidade de, somando-se a esses fatores, impactos das transformaçóes estruturais da economia chinesa, envolvendo o comércio, consumo e câmbio podem ter influenciado na queda desse período de 2015. Todavia, já em 2016 há sinais de retomada dos depósitos em RMB. Isso se deu em função de movimentos de abertura e aumento da complexidade do mercado offshore de Hong Kong, e isso se manteve até a metade de 2018 (IMI,2017).
A questão da abertura da conta de capitais, que se relaciona com uma maior liberalização das praças offshore e uma maior ligação dessas com o sistema financeiro chinês onshore são importantes para a China. Mesmo havendo diagnósticos favoráveis apontando como um caminho inevitável de maior flexibilização (SUBACCHI e OXENFORD, 2017; LIN et AL., 2017), isso é controverso, pois a relação comercial da China com o mundo ainda possui vinculação forte com sua capacidade de manter câmbio sob seu controle, e se proteger de ataques especulativos ou fragilidades ocasionadas pelos fluxos livres de capitais (CINTRA e PINTO, 2017).

Portanto um caminho novo, que aumente o uso do RMB associado a um controle da autoridade chinesa sobre seus rumos é essencial, e passa pelos elementos apontados nessa seçấo.

\section{CONCLUSÃO}

Schweller (2018) mostra que a China possui ambiçóes de se tornar uma potência, voltando-se para fora e construindo alianças e maneiras de se colocar como grande potência, desafiando o poder americano, mas sem que isso seja necessariamente uma chamada ao belicismo. 
Do outro lado, o poder americano ainda se faz presente. Na questão monetária é possível observar que sua influência e poder são relevantes, logo sendo um primeiro desafio para o projeto chinês entrar no rol de moedas internacionalizadas (plenamente conversíveis ${ }^{17}$, e em seguida estar nas moedas de grande relevância, (Top Currencies) ${ }^{18}$, em consonância com o projeto chinês de ser uma potência em todas as áreas.

Por fim, foi possível observar uma série de nuances na trajetória de ascensão do uso internacional da sua moeda, é possível afirmar que após a crise de 2008 a moeda chinesa conseguiu maior relevância, maior entrada internacional, mas sem preencher de maneira satisfatórias as funções de unidade de conta, reserva de valor, e meio de troca. Isso se deu pelo entrave que o SFMI apresenta, que pode ser caracterizado pela necessidade de adequação a liberdade de fluxos de capitais, desregulamentações em prol dos mercados financeiros, em que o país líder de tal processo é os EUA.

O dilema chinês está em fazer com que sua moeda seja utilizada, porém adotando políticas diferentes das tradicionais, com alternativas para que sua moeda seja utilizada por agentes privados e estatais, sem que isso signifique a perda da sua autonomia de formulação de políticas econômicas.

Dentro dessa lógica, mesmo com algumas adversidades há perspectivas positivas para a China em relação aos acordos que serão fechados com diversos países no contexto da BRI, assim como em relação ao papel dos mercados offshore (como em Hong Kong) e uma ligaçáo onshore nesse processo

17. É importante ressaltar que mesmo a China estando no sistema Special Drawing Rights (SDR), dentro das premissas adotadas no presente artigo, ela não é considerada internacional e completamente conversível, precisando atender as características apontadas na seção 2. (COHEN, 1971 ; HELLEINER, 2008).

18. Em Cohen (1998), descrevem-se as Top Currencies como as moedas de maior uso internacional, e portanto que conferem ao país maior influência econômico internacional. para depósitos, compensaçóes, e no âmbito das finanças, com toda a sorte de serviços financeiros e modalidades de investimentos que possam tornar o RMB mais atrativo.

A despeito de haver muito potencial, a China precisa encontrar seu caminho em uma lógica financeira em que os EUA são líderes, e uma ativa participação do governo em termos de regulação e investimentos precisará acontecer para garantir tanto o projeto de ascensão da sua moeda ao nível de grande potência, quanto a proteçáo dos seus objetivos ligado ao desenvolvimento econômico para se tornar uma grande potência.

\section{Referências}

BRAGA, Jose Carlos de Souza. Financeirização Global: O padrão sistêmico de riqueza do capitalismo contemporâneo. In: TAVARES, Maria da Conceição; FIORI, Jose Luís. Poder e Dinheiro: Uma economia política da globalização. Petrópolis: Vozes, 1997. p. 195-242.

BRAGA, José Carlos de Souza; CINTRA, Marco Antônio Macedo. FINANÇAS DOLARIZADAS E CAPITAL FINANCEIRO: Exasperação sob o Comando Americano. In Fiori, J.L, Poder Americano. Petrópolis, Vozes, 2004.

CINTRA, M.A. ; PINTO, E.C.. CHINA EM TRANSFORMAÇÃO: Transição e Estratégias de Desenvolvimento. Revista de Economia Política, São Paulo, v. 2, n. 37, 2017 p. 381-400.

COHEN, B. J. THE BENEFITS AND COSTS OF AN INTERNATIONAL CURRENCY: getting the calculus right. Open Economies Review, v. 23, p. 13-31, 2011.

COHEN, B. J. THE FUTURE OF STERLING AS AN INTERNATIONAL CURRENCY. London: Macmillan, 1971.

COHEN, B. J. The Geography of Money. New York: Cornell University Press, p. 229. 1998

COHEN, B. J. The Yuan Tomorrow? Evaluating China's Currency Internationalisation Strategy. New Political Economy, [s.l.], v. 17, n. 3, p.361-371, jul. 2012.

CURRENCY COMPOSITION OF OFFICIAL FOREIGN EXCHANGE RESERV (COFER). International Monetary Fund. Disponível em: http://data.imf.org/?sk=E6A5F467-C14B-4AA8-9F6D-5A09EC4E62A4 Acesso em: 20 ago. 2018.

EICHENGREEN, B. Exorbitant privilege : The Rise and Fall of the Dollar and the Future of the International Monetary System. Oxford. Oxford University Press, 2011. 
GAGNON, Joseph E; TROUTMAN, Kent. INTERNATIONALIZATION OF THE RENMINBI: The role of Trade Settlement. Washington: Peterson Institute For International Economics, 2014

HELLEINER, Eric. A Bretton Woods moment? The 2007-2008 crisis and the future of global finance. International Affairs, Oxford, v. 86, n. 3, p.619-636, Oxford University Press, 2010.

HELLEINER, Eric. Political Determinants of International Currencies: what future for the us dollar?. Review Of International Political Economy, [s.1.], v. 15, n. 3, 2008 p.354-378.

HELLEINER, Eric; KIRSHNER, Jonathan. THE FUTURE OF THE DOLLAR: Whiter the Key Currency. In: HELLEINER, Eric; KIRSHNER, Jonathan. The Future of The Dollar. New York: Cornell University Press, 2009. p. 1-23. 250p.

HONG KONG MONETARY AUTHORITY (HKMA). 2018. Disponível em: https://www.hkma.gov.hk/eng/market-data-and-statistics/monetary-statistics/monetary-base/2018/. Acesso em: 15 ago. 2018.

INTERNATIONAL MONETARY INSTITUTE (IMI). RMB Internationalization Report Jul. 2017. Disponível em: http:// www.imi.org.cn/en/?p=3128. Acesso em: 28 de ago. 2018,

KALTENBRUNNER, Annina; LYSANDROU, Photis. The US Dollar's Continuing Hegemony as an International Currency: A Double-matrix Analysis. Development And Change, [s.l.], v. 48, n. 4, p.663-691, 2017.

KIRSHNER, J. After the (Relative) Fall: Dollar Diminution and the Consequences for American Power. In: HELLEINER, Eric; KIRSHNER, Jonathan. The Future of The Dollar. New York: Cornell University Press, p. 191-216, 2009.

KIRSHNER, Jonathan. Dollar Diminution and New Macroeconomic Constraints on American Power. In: SURI, Jeremi; VALENTINO, Benjamin. Sustainable Security: Rethinking American National Security Strategy. Oxford: Oxford University Press, p. 1-41, 2016.

LIN, X. et al. A Research on the Belt and Road Initiatives and Strategies of RMB Internationalization. Business And Management Research, Sciedu Press ,[s.l.], v. 6, n. 1, p.13-28, 23 jan, 2017.

MCDOWELL, D. The US as 'Sovereign International Last-Resort Lender': The Fed's Currency Swap Programme during the Great Panic of 2007-09. New Political Economy, Charsllotsville, v. 17, n. 2, p.157-178, 2012.

MCNALLY, Christopher A.; GRUIN, Julian. A novel pathway to power? Contestation and adaptation in China's internationalization of the RMB. Review of International Political Economy, [s.1.], v. 24, n. 4, 2017. p.599-628.

SCHWELLER, Randall. Opposite but Compatible Nationalisms: A Neoclassical Realist Approach to the Future of USChina Relations. The Chinese Journal Of International Politics, [s.l.], v. 11, n. 1, p.23-48, 2018.
SERRANO, Franklin. Do ouro imóvel ao dólar flexível. Economia e Sociedade, Campinas, v. 11, n. 2, p.237-253, jul. 2002.

STEPHEN, M. D.. Rising powers, global capitalism and liberal global governance: A historical materialist account of the BRICs challenge. European Journal of International Relations, [s.l.], v. 20, n. 4, p.912-938, 2014.

SUBACCHI, P.; OXENFORD, M. The 'Belt and Road' Initiative and the London Market: the Next Steps in Renminbi Internationalization. Chatam House: The Royal Institute of International Affairs, Londres, p.1-31, jan. 2017.

SUBACCHI, Paola. ONE CURRENCY, TWO SYSTEMS: China’s Renminbi Strategy. [Sl]: Chatham House, 2010.

WANG, You; CHEN, Dingding. Rising Sino-U.S. Competition in Artificial Intelligence. China Quarterly Of International Strategic Studies, [s.1.], v. 04, n. 02, p.241-258, jan. 2018.

YUAN, Ping-hong. Trade Strategy Adjustment of China After the Financial Crisis. The Chinese Economy, [s.l.], v. 50, n. 2, p.112-118, 25 jan. 2017.

WORLD BANK.World Bank Database Disponível em: https://databank. worldbank.org/data/reports. aspx?source $=2 \&$ country=CHN. Acesso em: 22 ago. 2018. 